\title{
Age-dependent impact of zygosity and birth weight on insulin secretion and insulin action in twins
}

\author{
P. Poulsen ${ }^{1}$, K. Levin 1 , H. Beck-Nielsen ${ }^{1}$, A. Vaag ${ }^{2}$ \\ ${ }^{1}$ Diabetes Research Centre, Department of Endocrinology, Odense University Hospital, Odense, Denmark \\ ${ }^{2}$ Steno Diabetes Centre, Gentofte, Denmark
}

\section{Abstract}

Aims/hypothesis. Study the influence of age, zygosity and birth weight on insulin action and insulin secretion in twins.

Methods. In vivo insulin action and insulin secretion were measured using the euglycaemic, hyperinsulinaemic clamp technique and intravenous glucose tolerance test, respectively. We examined 104 monozygotic (MZ) twins and 88 dizygotic (DZ) twins in two age groups (25-34 and 57-66 years).

Results. There were no differences in birth weight, body mass index, waist to hip ratio or lean body mass between monozygotic and dizygotic twins. Younger monozygotic twins had a slightly higher insulin-stimulated glucose uptake (M) than younger dizygotic twins. In contrast, elderly monozygotic twins had a lower insulin-stimulated glucose uptake value compared with elderly dizygotic twins. Elderly monozygotic twins had a reduced insulin secretion relative to insulin resistance compared to dizygotic twins during oral glucose tolerance test (OGTT). Birth weight per se was not associated with insulin secretion or action in the twins. However, correcting for the genetic influence on birth weight using intrapair differences among monozygotic twin pairs, low birth weight was associated with insulin resistance and low insulin secretion after both oral and intravenous glucose administration in elderly MZ twins.

Conclusion/interpretation. Zygosity status has a major age (or time) dependent impact on in vivo insulin secretion and insulin action in twins independent of birth weight and adult antropometry. An additional non-genetic impact of low birth weight on insulin secretion and insulin action was found in elderly monozygotic twins. Ageing could play an important role by unmasking the influence of an adverse intrauterine environment on insulin resistance and low insulin secretion in twins. [Diabetologia (2002) 45:1649-1657]

Keywords Twins, zygosity, Type 2 diabetes, insulin secretion, insulin resistance.
Several epidemiological studies have indicated an influence of the intrauterine environment and in particular of low birth weight for the development of Type II (non-insulin-dependent) diabetes mellitus later in life [1-5]. The influence is believed to be mediated

Received: 18 March 2002 / Revised: 12 August 2002

Published online: 9 November 2002

(C) Springer-Verlag 2002

Corresponding author: P. Poulsen, MD, PhD, Diabetes Research Centre, Department of Endocrinology, Odense University Hospital, 5000 Odense C, Denmark. E-mail: ppoulsen@health.sdu.dk Abbreviations: MZ, Monozygotic; DZ, dizygotic; M, insulinstimulated glucose uptake; Di, disposition index. through "foetal organ programming" [6]. Metabolic studies among humans and in particular among rodents have shown permanent changes in the structure and/or function of involved organs after exposure to an adverse intrauterine environment during critical stages of foetal development leading to the development of two major metabolic abnormalities responsible for the development of overt Type II diabetes i.e. impaired insulin secretion $[7,8,9,10,11,12]$ and insulin resistance $[13,14,15,16,17,18,19]$. However, most human studies have used indirect techniques to measure insulin action including hyperinsulinaemia, HOMA or insulin sensitivity index (MINMOD) [13, $14,15,18]$, and several studies have failed to show 
any impact of low birth weight or the intrauterine environment on in vivo insulin secretion in man [7, $15,18]$.

Intrauterine malnutrition and foetal growth restriction is more likely to occur in twins compared to singletons because of their shared uterine environment [20]. Monozygotic (MZ) twins are often monochorionic and share the same placenta. Due to sharing of the same nutritive source and the development of vascular anastamoses, monochorionic twins could have a different and possibly more adverse intrauterine environment compared to dizygotic (DZ) and dichorionic MZ twins having separate placentas [21]. According to the foetal programming hypothesis MZ twins could therefore be more prone to develop various metabolic abnormalities.

We have recently shown increased glucose and insulin areas under the curves after oral glucose ingestion in elderly $\mathrm{MZ}$ twins compared with DZ twins supporting the hypothesis of an impact of zygosity status for the development of insulin resistance among twins [22]. These results, however, were based upon indirect estimates of insulin resistance (i.e. oral glucose tolerance test).

Age could be one of the most important factors precipitating the metabolic abnormalities characterising Type II diabetes [23, 24], and the influence of the intrauterine environment for the development of insulin resistance and other metabolic abnormalities could vary with age potentially becoming more pronounced with increasing age as indicated in a few rodent studies $[25,26]$.

In this study we investigated the impact of zygosity status and birth weight on in vivo insulin secretion and insulin-action based upon "gold standard" methods in a young twin and elder twin cohort. In particular, insulin secretion was expressed in relation to insulin action acknowledging the inverse hyperbolic relationship between insulin secretion and insulin action [27] thereby providing an accurate estimate of the pancreatic beta-cell function. Information about length of gestation, birth length and in particular birth weight was obtained from the original midwife records. Intratwin pair correlation analyses were carried out among MZ twin pairs to assess if a non-genetically determined low birth weight could be associated with defects in insulin secretion and/or insulin action.

\section{Subjects and methods}

Subjects. Subjects were identified through The Danish Twin Register [28, 29, 30]. A random extract of same sex monozygotic (MZ) and dizygotic (DZ) twin pairs born in Funen County from 1931 to 1940 (57-66 years) and 1966 to 1975 (22-31 years) with available original midwife records including birth weight and length were initially included. All potential subjects identified according to these inclusion criteria were contacted and interviewed in order to exclude subjects fulfilling the exclusion criteria. The exclusion criteria were as following: Either twin from the pair not willing to participate, information of pre- or post maturity (birth $>$ or $<$ than 3 weeks from expected time point), known diabetes, serious heart, liver or kidney disease, medication with influence on glucose or lipid metabolism including oral contraception which could not be withdrawn and pregnancy/lactation.

A total of 98 twin pairs (33 younger monozygotic; 22 younger dizygotic; 21 elder monozygotic; 22 elder dizygotic) were included in the clinical examination, including an oral glucose tolerance test (OGTT). Among the elder MZ twins 76.2\% had normal glucose tolerance (NGT), $19.0 \%$ had impaired glucose tolerance (IGT) and $4.8 \%$ had previously unknown Type II diabetes. Among elder DZ twins $72.7 \%$ had NGT, 25.0\% had IGT and $2.3 \%$ had previously unknown Type II diabetes. All younger DZ twins had NGT and among younger MZ twins $97.0 \%$ were glucose tolerant and $3.0 \%$ had IGT. There was no significant difference in glucose tolerance status between MZ and DZ twins within each age group. Zygosity was determined by serological testing, the most valid method with a success rate exceeding $99 \%$ [31]. The study was approved by the regional ethics committees and the study was conducted according to the principles of the Helsinki Declaration.

Clinical examination. Subjects underwent a 2-day clinical examination separated by 1 to 2 weeks. The twins in each pair were investigated simultaneously. The subjects were instructed to abstain from strenuous physical activity for $24 \mathrm{~h}$ and to fast for $10-12 \mathrm{~h}$ before both examination days.

Day 1 included a standard 75 g OGTT. Peripheral venous blood was taken before oral glucose ingestion and subsequently 30, 60 and $120 \mathrm{~min}$ later. Weight and height were measured with the subjects in lightweight clothes with shoes removed and the BMI (weight $(\mathrm{kg}) /$ height $\left(\mathrm{m}^{2}\right)$ ) was calculated. Waist circumference was measured using a soft tape on standing subjects midway between the lowest rib and the iliac crest. Hip circumference was measured over the widest part of the gluteal region, and the waist to hip ratio was calculated accordingly. Body composition, i.e. lean body mass and fat mass, was determined by DEXA scanning.

On day 2 subjects underwent a 2 -h hyperinsulinaemic, euglycaemic clamp $\left(40 \mathrm{mU} \cdot \mathrm{m}^{-2} \cdot \mathrm{min}^{-1}\right)$ preceded by a $30 \mathrm{~min}$ intravenous glucose tolerance test (IVGTT). Polyethylene catheters were placed in the antecubital vein for infusion and in the contralateral dorsal hand or antecubital vein for blood sampling. This "sampling" hand was placed in a heated Plexiglas box to ensure arterialization of the venous blood sample. After a 2-h basal period an intravenous glucose bolus $(0.3 \mathrm{~g} / \mathrm{kg}$ body weight) was given over $1 \mathrm{~min}$. Blood samples for glucose and insulin measurements were drawn at 0, 2, 4, 6, 8, 10, 15, 20 and $30 \mathrm{~min}$. After the IVGTT a primed-continuous insulin infusion $\left(40 \mathrm{mU} \cdot \mathrm{m}^{-2} \cdot \mathrm{min}^{-1}\right)$ was initiated and continued for $2 \mathrm{~h}$. A steady state was defined as the last $30 \mathrm{~min}$ of the $2 \mathrm{~h}$ clamp period. A variable infusion of glucose $(180 \mathrm{~g} / \mathrm{l})$ maintained euglycaemia during insulin infusion. Plasma glucose concentration was monitored every 5 to $10 \mathrm{~min}$ during the basal and clamp periods using an automated glucose oxidation method (Glucose Analyser 2, Beckman Instruments, Fullerton, Calif., USA). Blood samples were drawn for measurements of glucose and insulin every 10 to 30 min during the basal and clamp steady state periods.

Analytical methods. Plasma glucose concentrations were analysed by the glucose dehydrogenase oxidation method. Plasma insulin concentrations were measured using a two-site, twostep, time resolved immunofluoremetric assay (DELFIA, Turku, Finland) as previously described [32]. Cross reactivities 
Table 1. Clinical characteristics. Data presented as mean (SD)

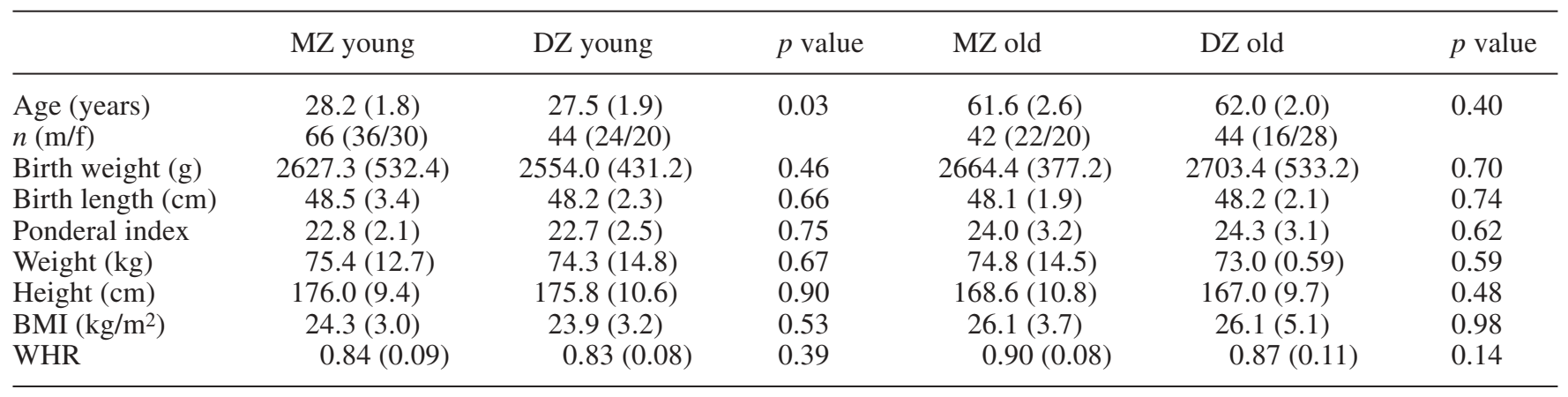

with proinsulin, C-peptide and Des-split $[31,32]$ product in the insulin assay were all less than $0.4 \%$. Intraassay coefficients of variation in the physiological ranges were 3.6 to $4.3 \%$ for plasma insulin. Interassay coefficients of variation were 1.7 to $3.4 \%$ for plasma insulin.

Calculations. Oral glucose tolerance test. The total and incremental glucose and insulin areas under the curves (AUC) during OGTT were calculated for the initial $30 \mathrm{~min}$ period and for the entire $120 \mathrm{~min}$ period $\left(\mathrm{AUC}_{0-30}\right.$, incAUC $\mathrm{AL}_{030}$ and $\mathrm{AUC}_{0-120}$, inc $\left.\mathrm{AUC}_{0-120}\right)$. The incremental insulin secretion, Ins $_{\text {inc0-30 }}$, was defined as $\left(\left(\mathrm{ins}_{30}-\mathrm{ins}_{0}\right) \times 10^{-9} /\left(\mathrm{glu}_{30}-\mathrm{glu}_{0}\right)\right)$.

Intravenous glucose tolerance test. The total and incremental glucose and insulin areas under the curves (AUC) during IVGTT were calculated for the initial $10 \mathrm{~min}$ period $\left(\mathrm{AUC}_{0-10}\right.$ and inc $\left.\mathrm{AUC}_{0-10}\right)$. First phase insulin secretion was defined as incAUC $\mathrm{AU}_{0-10}$. Insulin response in relation to the glucose concentration (phi) was calculated as the AUC for insulin divided by the AUC for glucose during the initial $10 \mathrm{~min}$ of the IVGTT $\left(\mathrm{AUC}_{\mathrm{ins} 0-10} \times 10^{-9} / \mathrm{AUC}_{\mathrm{glu} 0-10}\right)$.

Hyperinsulinaemic and euglycaemic clamp. Insulin-stimulated glucose uptake, M, was defined as the glucose infusion rate during steady state. The M-values were expressed per $\mathrm{kg}$ lean body mass as determined by DEXA scan.

Disposition indices. We calculated disposition indices (Di) in order to estimate the insulin secretion capacity in relation to insulin sensitivity acknowledging the inverse hyperbolic relationship between insulin secretion and insulin action (insulin secretion $\times$ insulin action). Di OGTT was calculated as $\left(\right.$ Ins $\left._{\text {inc0-30 }} \times \mathrm{M}\right)$. Di $\mathrm{i}_{\text {IVGTT }}$ was calculated as $\left(\mathrm{Phi}_{\text {IVGTT }} \times \mathrm{M}\right)$.

Statistical methods. The variables were almost normally distributed and comparisons between MZ and DZ twins within each age group were therefore carried out using parametric analysis (Students $t$ tests) for unpaired data. All tests were twotailed. Phenotypic correlations and intra-twin pair correlation analyses were done using Pearsons correlation. A $p$ value of less than or equal to 0.05 was considered statistically significant. Data are shown as mean (SD).

\section{Results}

Clinical characteristics. The MZ twins were unintentionally slightly older compared with the DZ twins in the younger age group (Table 1). Besides this, MZ and DZ twins were similar regarding current weight,
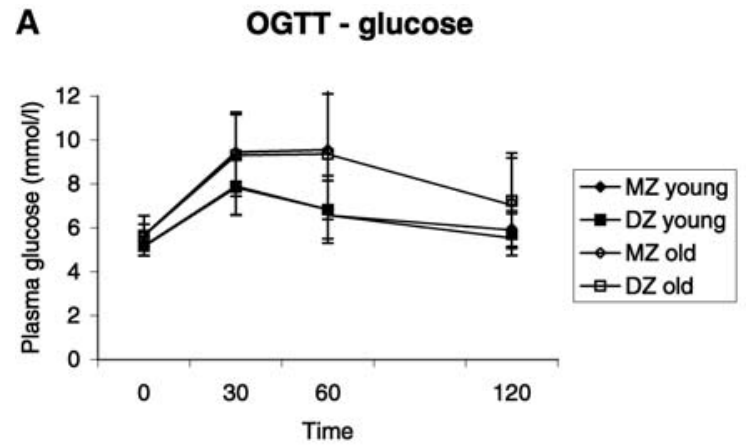

B IVGTT - glucose

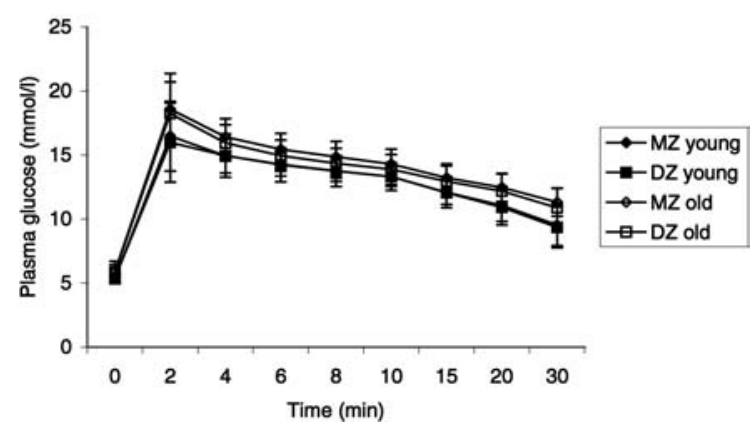

Fig. 1. A Plasma glucose during OGTT among younger and elder MZ and DZ twins. Data are means \pm SD. B Plasma insulin during OGTT among younger and elder MZ and DZ twins. Data are means \pm SD

height, BMI and WHR within each age group. Furthermore, no differences were found in birth weight, birth length or ponderal indices between $\mathrm{MZ}$ and $\mathrm{DZ}$ twins in either age group, Table 1.

Oral glucose tolerance test. Fasting plasma glucose concentrations were similar among the younger $\mathrm{MZ}$ and DZ ( MZ: $5.2(0.4)$ vs. DZ: $5.2(0.4), p=0.80)$ and among the elder MZ and DZ twins (MZ: 5.7 (0.5) vs. DZ: $5.7(0.9), p=0.96)$. Furthermore, the plasma glucose concentrations at time points 30,60 and $120 \mathrm{~min}$ together with the area under the curve (AUC) for glucose were not statistically different between MZ and DZ twins within each age group (Table 2, Fig. 1A). 
Table 2. Oral glucose tolerance test. Data presented as mean (SD)

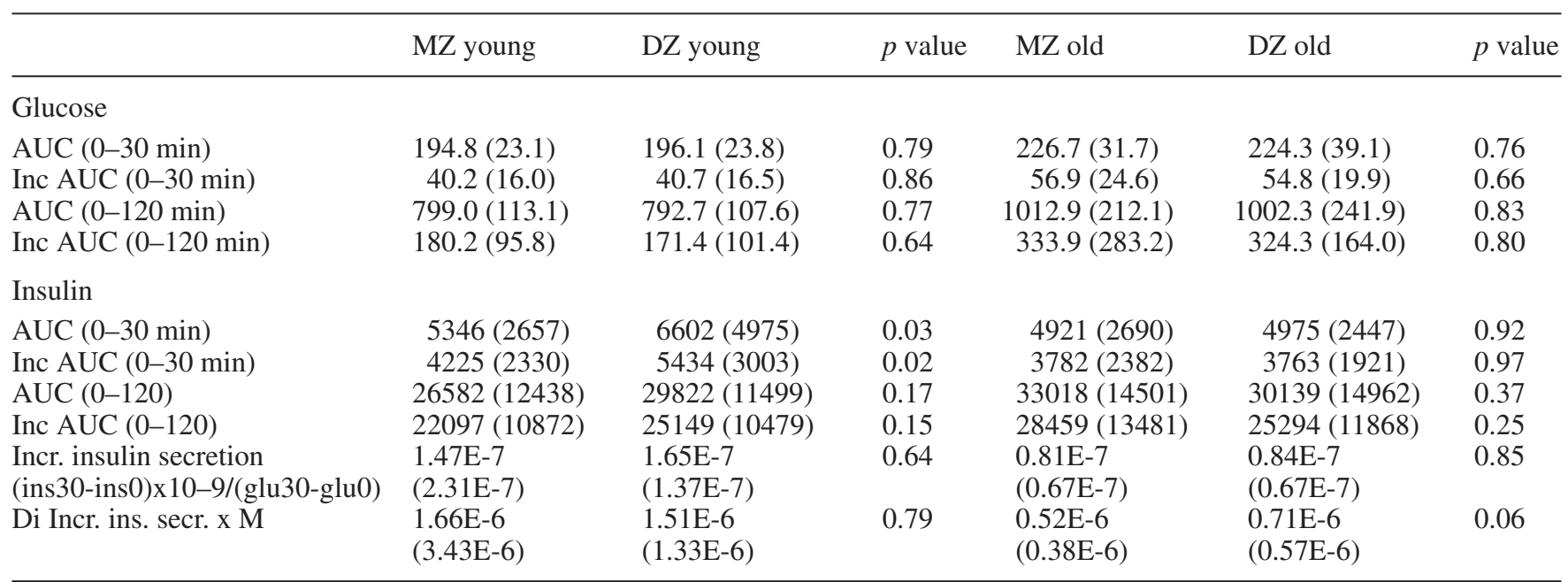

Fasting plasma insulin concentrations were similar among the younger MZ and DZ twins ( MZ: 37.4 (18.4) vs DZ: 38.9 (16.9), $p=0.65$ ) and the elder MZ and DZ twins (MZ: 38.0 (16.3) vs DZ: 40.4 (35.6), $p=0.69$ ). Furthermore, among elder twins there were no differences in plasma insulin concentrations at time points 30,60 and $120 \mathrm{~min}$ or AUC for insulin between MZ and DZ twins. However, among the younger twins, MZ twins had a lower 30 min plasma insulin concentration together with a lower AUC 0 to 30 and incremental AUC 0 to 30 for insulin compared to DZ twins (Fig. 1B and Table 2). Despite these differences, there was no difference in incremental insulin secretion between MZ and DZ twins in either age group. However, when expressing insulin secretion in relation to insulin sensitivity by means of $\mathrm{Di}, \mathrm{MZ}$ twins showed lower insulin secretion compared to DZ among the elder twins (MZ: 0.52E-6 (0.38E-6); DZ: $0.71 \mathrm{E}-6(0.57 \mathrm{E}-6), p=0.06)$, indicating that early insulin secretion is influenced by zygosity status. No such difference was detected among the younger twins.

Intravenous glucose tolerance test. No differences were seen in plasma glucose concentrations or AUC for glucose between MZ and DZ twins within each age group (Fig. 2A and Table 3). Among younger twins, DZ twins had an insignificant but higher AUC 0 to 10 and first phase insulin secretion compared to MZ twins (Fig. 2B and Table 3). Absolute insulin concentrations throughout the IVGTT, peak insulin concentration and first phase insulin secretion were similar among elderly MZ and DZ twins. In contrast to the findings during OGTT, we found similar early insulin response in relation to insulin resistance (Di) among $\mathrm{MZ}$ and DZ twins within both age groups.

Hyperinsulinaemic and euglycaemic clamp. Glucose concentrations during basal and insulin-stimulated steady state conditions were similar between MZ and

\section{A OGTT - insulin}

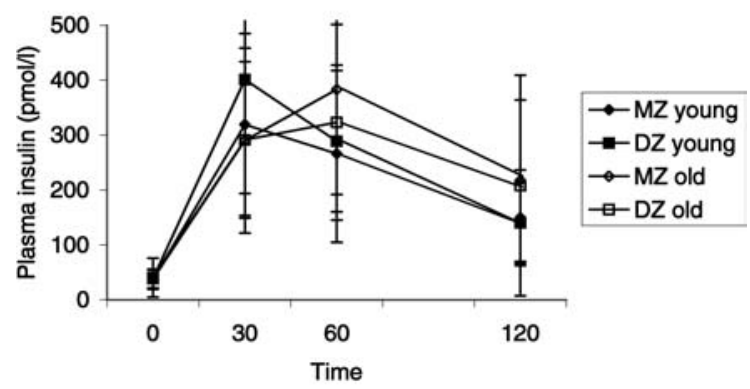

B IVGT - insulin

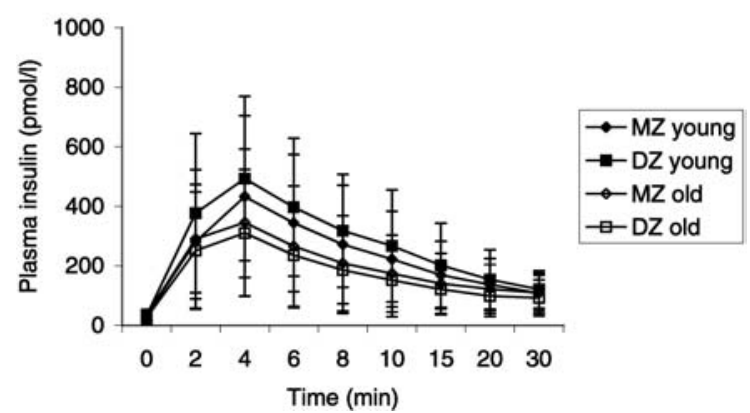

Fig. 2. A Plasma glucose during IVGTT among younger and elder MZ and DZ twins. Data are means \pm SD. B Plasma insulin during IVGTT among younger and elder MZ and DZ twins. Data are means \pm SD

DZ twins in each age group (data not shown). The insulin-stimulated glucose uptake rate during steady state (M) expressed per $\mathrm{kg}$ lean body mass was lower among elder MZ compared to elder DZ twins (MZ: 7.0 (3.3); DZ: 9.4 (3.3), $p=0.002$ ). In contrast, we found a higher insulin action among MZ twins compared to DZ twins in the younger age group (MZ: 10.7 (3.3); DZ: 9.3 (2.8), $p=0.03)$, Table 4. 
Fig. 3. Intra-twin correlations between differences in birth weight and $\mathrm{M}$ among elderly MZ and DZ twins

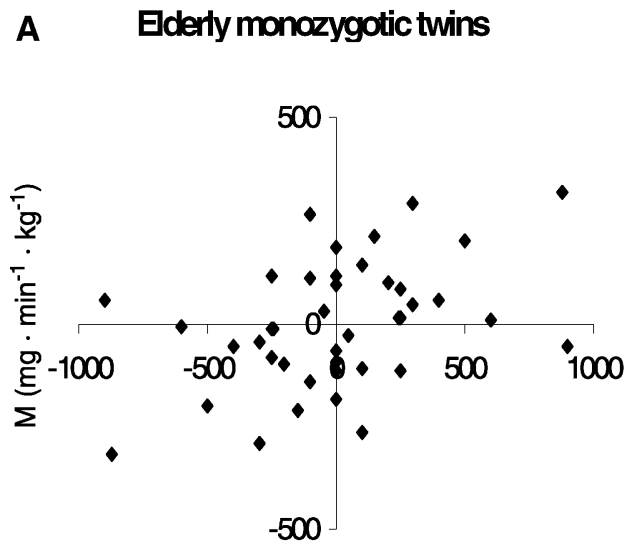

Birth weight $(g)$
B Elderly dizygotic twins

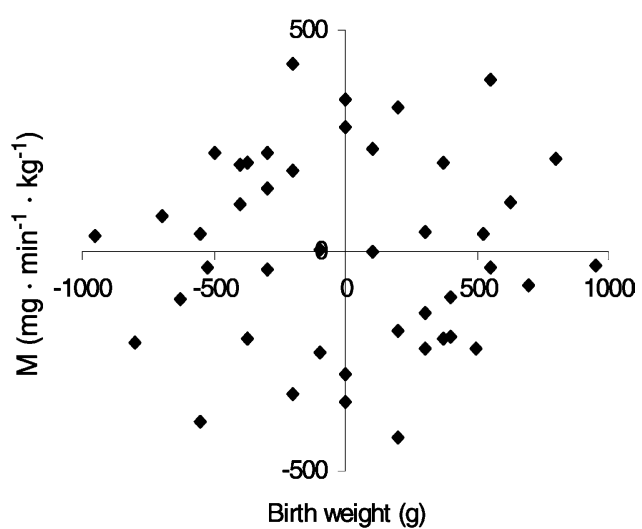

Table 3. Intravenous glucose tolerance test (IVGTT). Data presented as mean (SD)

\begin{tabular}{|c|c|c|c|c|c|c|}
\hline & MZ young & DZ young & $p$ value & MZ old & DZ old & $p$ value \\
\hline \multicolumn{7}{|l|}{ Glucose } \\
\hline AUC (0-10 min) & $137.6(11.2)$ & $136.5(15.0)$ & 0.69 & $150.8(13.4)$ & $146.6(13.2)$ & 0.17 \\
\hline Inc AUC (0-10 min) & $83.7(10.4)$ & $82.6(13.1)$ & 0.64 & $91.7(11.2)$ & $88.2(9.0)$ & 0.14 \\
\hline \multicolumn{7}{|l|}{ Insulin } \\
\hline AUC (0-10 min) & $2914.6(1809.5)$ & $3473.0(2021.4)$ & 0.15 & $2429.2(1750.2)$ & $2149.0(1530.5)$ & 0.46 \\
\hline Phi $\left(\mathrm{AUC}_{\mathrm{ins} 0-10}\right.$ X 10-9/AUC $\left.\mathrm{glu}_{\mathrm{gl}-10}\right)$ & $\begin{array}{l}2.12 \mathrm{E}-8 \\
(1.32 \mathrm{E}-8)\end{array}$ & $\begin{array}{l}2.56 \mathrm{E}-8 \\
(1.49 \mathrm{E}-8)\end{array}$ & 0.12 & $\begin{array}{l}1.60 \mathrm{E}-8 \\
(1.10 \mathrm{E}-8)\end{array}$ & $\begin{array}{l}1.48 \mathrm{E}-8 \\
(1.08 \mathrm{E}-8)\end{array}$ & 0.62 \\
\hline Di (Phi x M) & $\begin{array}{l}2.11 \mathrm{E}-7 \\
(1.14 \mathrm{E}-7)\end{array}$ & $\begin{array}{l}2.32 \mathrm{E}-7 \\
(1.39 \mathrm{E}-7)\end{array}$ & 0.42 & $\begin{array}{l}1.10 \mathrm{E}-7 \\
(0.78 \mathrm{E}-7)\end{array}$ & $\begin{array}{l}1.32 \mathrm{E}-7 \\
(0.92 \mathrm{E}-7)\end{array}$ & 0.26 \\
\hline
\end{tabular}

Table 4. Euglycaemic hyperinsulinaemic clamp - insulin-stimulated glucose uptake (M). Data presented as mean (SD)

\begin{tabular}{lllllll}
\hline & MZ young & DZ young & P value & MZ old & DZ old & $p$ value \\
\hline $\mathrm{M} / \mathrm{kg} \mathrm{LBM} \mathrm{(mg/kg/min)}$ & $10.7(3.3)$ & $9.3(2.8)$ & 0.03 & $7.0(3.3)$ & $9.4(3.3)$ & 0.002 \\
\hline
\end{tabular}

Phenotypic correlations. Except for a positive correlation between $\mathrm{M}$ and ponderal index among young MZ ( $r=0.39, p=0.002)$, no significant correlations were seen between measures of insulin resistance and absolute birth parameters (i.e. birth weight and ponderal index). However, when correlating the intrapair differences, a positive correlation was seen between $\mathrm{M}$ and ponderal index among young DZ $(r=0.34$, $p=0.03$ ), and between $\mathrm{M}$ and birth weight among elder MZ twins (Table 5, Fig. 3). Absolute values of insulin secretion during OGTT $\left(\mathrm{Di}_{\text {OGTT }}\right)$ did not correlate with birth weight or ponderal index. Among elder MZ and DZ twins intrapair differences in $\mathrm{Di}_{\text {OGTT }}$ correlated positively with intrapair differences in birth weight (MZ: $r=0.37, p=0.02$; DZ: $r=0.35, p=0.02$, Table 6 ), whereas a negative intrapair correlation was seen between birth weight and $\mathrm{Di}_{\text {OGTT }}$ among young $\mathrm{MZ}$ twins. Insulin secretion during IVGTT, Di $\mathrm{IVGTT}_{\text {IVT }}$ correlated positively with
Table 5. Correlation coefficients between birth weight and $\mathrm{M}$

\begin{tabular}{lll}
\hline Subjects $(n)$ & \multicolumn{2}{l}{ Birth weight vs $\mathrm{M}$} \\
\cline { 2 - 3 } & Absolute & Intrapair difference \\
\hline Young & & \\
MZ (64) & 0.02 & -0.11 \\
DZ (40) & 0.21 & 0.15 \\
Old & & \\
MZ (42) & 0.08 & $0.42^{\mathrm{a}}$ \\
DZ (44) & -0.08 & -0.002 \\
\hline
\end{tabular}

a $p<0.01$

ponderal index among young MZ twins ( $r=0.26$, $p=0.04)$. When correlating intrapair differences, $\mathrm{Di}_{\text {IVGTT }}$ correlated negatively with birth weight among young MZ twins and positively with birth weight among elder MZ twins (Table 7). 
Table 6. Correlation coefficients between birth weight and $\mathrm{Di}_{\text {OGTT }}$

\begin{tabular}{lcc}
\hline Subjects (n) & \multicolumn{2}{c}{ Birth weight vs Di OGTT } \\
\cline { 2 - 3 } & Absolute & Intrapair difference \\
\hline Young & & \\
MZ (64) & -0.10 & $-0.26^{\mathrm{a}}$ \\
DZ (40) & 0.26 & 0.01 \\
Old & & \\
MZ (42) & 0.04 & $0.37^{\mathrm{b}}$ \\
DZ (44) & 0.13 & $0.35^{\mathrm{b}}$ \\
\hline
\end{tabular}

${ }^{\mathrm{a}} p=0.04,{ }^{\mathrm{b}} p=0.02$

Table 7. Correlation coefficients between birth weight and $\mathrm{Di}_{\text {IVGTT }}$

\begin{tabular}{lcl}
\hline Subjects (n) & \multicolumn{2}{c}{ Birth weight vs Di $_{\text {IVGTT }}$} \\
\cline { 2 - 3 } & Absolute & Intrapair differences \\
\hline Young & & \\
MZ (64) & -0.13 & $-0.30^{\mathrm{a}}$ \\
DZ (36) & 0.09 & -0.03 \\
Old & & \\
MZ (42) & 0.24 & $0.43^{\mathrm{b}}$ \\
DZ (36) & 0.03 & -0.08 \\
\hline
\end{tabular}

${ }^{\mathrm{a}} p=0.02,{ }^{\mathrm{b}} p<0.01$

\section{Discussion}

Our study shows that elderly MZ twins have metabolic abnormalities including insulin resistance and a disproportionately reduced insulin secretion in relation to insulin action compared with DZ twins. These findings are consistent with our previous findings providing mechanistic explanations for the increased plasma glucose and insulin profiles after oral glucose ingestion in MZ compared with DZ twins [22]. These differences between $\mathrm{MZ}$ and $\mathrm{DZ}$ twins were independent of the available parameters related to birth (i.e. birth weight, length and ponderal index) and adult anthropometry. The influence of zygosity status on insulin secretion and insulin-action showed a strong age - or time dependency as the metabolic defects associated with zygosity status first appeared with advanced age. In fact, in young age MZ twins showed a transient or initial favourable insulin action as compared to DZ twins. Whereas birth weight per se did not explain the impact of zygosity status on insulin secretion and action, we did in fact, using intra-pair correlation analyses in MZ twin pairs, find evidence of a non-genetically determined association between low birth weight and decreased insulin secretion as well as insulin- action in the elderly twins. Using this complementary approach to address the possible impact of the intrauterine environment in twins, we found some evidence of opposite relationships in young as compared with elderly twins. Thus, low birth weight was associated with a non-genetically determined disproportionately increased insulin secretion after both oral and intravenous glucose administration in young MZ twins, with a tendency towards an improved insulin action in young MZ twins. In contrast, low birth weight was associated with low insulin secretion as well as insulin action in the elderly MZ twins. Consequently, the two independent ways of analysing the present twin data both support the conclusion that ageing could play an important role in unmasking the influence of an adverse intrauterine environment on insulin resistance and low insulin secretion in twins.

Studies on twin birth weights are rather inconsistent, however, chorionicity seems to be the most important predictor of birth weight and hence foetal environment [20, 33, 34]. Two-thirds of MZ twins are monochorionic and share the same placenta. Consequently, MZ twins are thought to experience a more adverse intrauterine environment compared to DZ twins particularly due to the placental circumstances characterising MZ pregnancies [21]. In our study, however, MZ and DZ twins had similar birth weights and lengths. This indicates that the influence of an adverse intrauterine environment on organ programming and adult glucose and insulin metabolism goes beyond the influence of birth weight per se, which in turn is consistent with the hypothesis that birth weight could only provide a crude estimate of the intrauterine environment. Among other factors, genetics seem to be an important determinant of birth weight [35]. The correlations between intrapair differences permit matching for common environmental effects (i.e. shared maternal/placental environment) and, in particular, among the MZ twins for the influence of genotype. The correlations in the MZ twins between intra-pair differences in birth parameters on one side, and insulin resistance or insulin secretion on the other side, is therefore primarily a result of the individual foeto-placental environment. It was only after we corrected for the impact of genetics on birth weight using intra-pair correlations in MZ twin pairs that we were able to detect any influence of birth weight per se on insulin secretion and insulin action especially in the elder twins. The lack of any consistent intra-pair correlations between birth weights and insulin secretion or insulin action in the DZ twins could also be explained by the impact of genetics on both birth weights on one side, and insulin secretion and insulin-action on the other side. However, the correlations between birth weights and insulin action as well as insulin secretion in the MZ twin pairs are unique in the sense that they show that non-genetic factors such as the intrauterine nutrition in addition to genetics could play a role for the 
development of insulin resistance and defective insulin secretion in elderly twins.

In addition to similar birth anthropometry, we found similar adult anthropometry including current BMI, WHR and lean body mass between MZ and DZ twins in each age group. We were therefore able to control for several important factors with a documented influence on the metabolic variables, and in particular insulin action, measured in the study. Therefore, any differences shown in each age group could solely be explained by zygosity status per se.

While the lower insulin sensitivity among elder MZ twins compared to DZ twins is in accordance with what we expected from the thrifty phenotype hypothesis, and from our previous findings [22], the greater insulin sensitivity among younger MZ compared to DZ twins was unexpected and could seem somewhat surprising. However, this finding is in accordance with findings in animal models showing transient improved glucose tolerance and insulin sensitivity among young (3 months) male offspring of protein-malnourished rats [25, 26]. These studies in rats together with our findings in humans indicate the important role of age in unmasking the impact of an adverse intrauterine environment for the development of insulin resistance. Interestingly, this documented age dependence of the impact of zygosity status on insulin action and glucose metabolism might explain why another study was unable to find any differences in glucose and insulin concentrations among MZ compared with DZ twins with a mean age of 44 years and a total age range of only 4 years [36].

As opposed to our previous findings we were unable to find higher plasma glucose and insulin concentrations in the elderly MZ compared with DZ twins. An explanation for this could be the much smaller sample size in this study as compared to our previous study [22], and the fact that only non-diabetic subjects were included. Including only healthy subjects resulted in a reduced variation in plasma glucose and insulin concentrations making the detection of small differences in the comparisons between $\mathrm{MZ}$ and $\mathrm{DZ}$ twins more difficult. Nevertheless, using the "gold standard" euglycaemic hyperinsulinaemic clamp technique we provided conclusive evidence for the presence of insulin resistance in elderly $\mathrm{MZ}$ compared with DZ twins as suggested from the much more indirect estimates of insulin action in the larger number of twins in our previous study [22]. Another study reported a higher second phase insulin secretion in MZ compared to DZ twins during an IVGTT in elderly MZ compared with DZ twins [37] supporting our finding of insulin resistance in elderly twins. In contrast, we found higher insulin AUC during the initial 30-min period of the OGTT in young DZ compared to young MZ twins. However, the incremental insulin secretion and disposition index were similar. We believe that this increased insulin re- sponse to oral glucose is a compensatory mechanism to the documented lower insulin action among younger DZ twins in order to maintain normoglycaemia.

Accordingly, when evaluating insulin secretion it is important to take into account the inverse hyperbolic relation between insulin secretion and insulin action in vivo [27]. When expressing insulin secretion in relation to insulin sensitivity by means of disposition indices we found a reduced insulin secretion among elderly $\mathrm{MZ}$ compared to DZ twins after oral glucose administration, whereas we found similar insulin secretion in relation to insulin resistance in young MZ and DZ twins. Again, it is striking that low birth weight was associated with low insulin secretion in relation to insulin action (i.e. disposition indices) after both oral and intravenous glucose administration in the elderly MZ twin pairs, whereas the opposite was the case for the youngest $\mathrm{MZ}$ twin pairs (i.e. low birth weight was associated with increased insulin secretion in relation to insulin action). Therefore, the impact of age on insulin secretion disposition indices mimics the age dependency shown for the in vivo insulin action in the twins. Similarly, the insulin secretion results seem intrinsically consistent according to the age dependency regardless of whether the intrauterine component is estimated by the "zygosity criteria" or by birth weight intra-pair differences in the MZ twin pairs. It could be speculated that the biochemical mechanisms responsible for the age dependency of the early pre-programmed defects of both insulin secretion and insulin action might be similar.

The differences between MZ and DZ twins shown in this study challenges this major assumption of environmental (i.e. prenatal) similarity between $M Z$ and DZ twins and, therefore, to some extent further questions the validity of the classic twin approach evaluating the relative importance of genes compared with environment on a given phenotype [22, 37]. However, this is of course only to the extent that the investigated phenotype has a prenatal etiological component. Accordingly, the results of this study are primarily of importance for twin studies of Type II diabetes, insulin resistance and associated diseases such as hypertension, obesity and dyslipoproteinaemia.

In conclusion, zygosity per se has a major impact on both in vivo insulin secretion and insulin action in twins. The impact seems to be age-dependent or timedependent with a higher insulin action in younger and a lower insulin action in elderly MZ compared to DZ twins. The impact on insulin secretion was only apparent among elder twins with a lower insulin secretion in relation to insulin action in elder MZ compared to DZ twins. The impact of zygosity was not explained by differences in birth weights or other anthropometric measures usually associated with insulin action and insulin secretion. Nevertheless, in addition to the impact of zygosity status on glucose homeostasis, our study also showed non-genetic asso- 
ciations between low birth weight and defects of both insulin secretion as well as insulin action in elderly MZ twin pairs, and conversely between low birth weight and high insulin secretion in relation to insulin action in young $\mathrm{MZ}$ twins. Accordingly, the study provides additional support to the hypothesis of an intrauterine influence on the development of the pathophysiological mechanisms leading to Type II diabetes. Ageing could play an important role by in unmasking the influence of an adverse intrauterine environment on insulin resistance and low insulin secretion in twins.

\section{References}

1. Hales CN, Barker DJP, Clark PMS, Cox LJ, Osmond C, Winter PD (1991) Fetal and infant growth and impaired glucose tolerance at age 64. BMJ 303: 1019-1022

2. Phipps K, Barker DJP, Hales CN, Fall CHD, Osmond C, Clark PMS (1993) Fetal growth and impaired glucose tolerance in men and women. Diabetologia 36: 225228

3. Lithell HO, McKeigue PM, Berglund L, Mohsen R, Lithell U-B, Leon DA (1996) Relation of size at birth to non-insulin dependent diabetes and insulin concentrations in men aged 50-60 years. BMJ 312: 406-410

4. Poulsen P, Vaag AA, Kyvik KO, Jensen DM, BeckNielsen H (1997). Low birth weight is associated with NIDDM in discordant monozygotic and dizygotic twin pairs. Diabetologia 40: 439-446

5. Ravelli AC, van der Meulen JH, Michels RP et al. (1998) Glucose tolerance in adults after prenatal exposure to famine. Lancet 351: 173-177

6. Lucas A (1991) Programming by early nutrition in man. In: Bock GR, Whelan J (eds) The childhood environment and adult disease. Wiley, Chichester, pp 38-55

7. Phillips DIW, Hirst S, Clark PMS, Hales CN, Osmond C (1994) Fetal growth and insulin secretion in adult life. Diabetologia 37: 592-596

8. Robinson S, Walton RJ, Clark PM, Barker DJ, Hales CN, Osmond C (1992) The relation of fetal growth to plasma glucose in young men. Diabetologia 35: 444-446

9. Cook JT, Levy JC, Page RC, Shaw JA, Hattersley AT, Turner RC (1993) Association of low birth weight with beta cell funktion in adult first degree relatives of non-insulin dependent diabetic subjects. BMJ 306: 302-306

10. Dahri S, Snoeck A, Reusens-Billen B, Remacle C, Hoet JJ (1991) Islet function in offspring of mothers on lowprotein diet during gestation. Diabetes 40 [Suppl 2]: 115120

11. Desai M, Crowther NJ, Ozanne SE, Lucas A, Hales CN (1996) Adult glucose and lipid metabolism may be programmed during fetal life. Biochem Soc Trans 23: 331335

12. Holness MJ (1996) The influence of sub-optimal protein nutrition on the insulin secretion evoked by high-energy/ high-fat feeding in rats. FEBS Lett 396: 53-56

13. Phillips DIW (1996) Insulin resistance as a programmed response to fetal undernutrition. Diabetologia 39: 11191122

14. Phillips DIW, Barker DJP, Hales CN, Hirst S, Osmond C (1994) Thinness at birth and insulin resistance in adult life. Diabetologia 37: 150-154
15. Flanagan DE, Moore VM, Godsland IF, Cockington RA, Robinson JS, Phillips DIW (2000) Fetal growth and the physiological control of glucose tolerance in adults: a minimal model analysis. Am J Physiol Endocrinol Metab 278: E700-E706

16. McKeigue PM, Lithell HO, Leon DA (1998) Glucose tolerance and resistance to insulin-stimulated glucose uptake in men aged 70 years in relation to size at birth. Diabetologia 41: 1133-1138

17. Jaquet D, Gaboriau A, Czernichow P, Levy-Marchal C (2000) Insulin resistance early in adulthood in subjects born with intrauterine growth retardation. J Clin Endocrinol Metab 85: 1401-1406

18. Clausen JO, Borch-Johnsen K, Pedersen O (1997) Relation between birth weight and the insulin sensitivity index in a population sample of 331 young, healthy caucasians. Am J Epidemiol 146: 23-31

19. Desai M, Crowther NJ, Lucas A, Hales CN (1996) Organselective growth in the offspring of protein-restricted mothers. Br J Nutr 76: 591-603

20. Ramas-Arroyo MA, Ulbright TM, Yu PL, Christian JC (1988) Twin Study: relationship between birth weight, zygosity, placentation and pathologic placental changes. Acta Genet Med Gemellol (Roma) 37: 229-238

21. Langman J (1981) Fetal membranes and placenta. In: Medical embryology. Williams \& Wilkins, Baltimore London, pp 83-102

22. Poulsen P, Vaag A, Beck-Nielsen H (1999) Does zygosity influence the metabolic profile in twins? A population based cross sectional study. BMJ 319: 151-154

23. Reaven GM, Chen N, Hollenbeck C, Chen YDI (1989) Effect of age on glucose tolerance and glucose uptake in healthy individuals. J Am Geratr Soc 37: 735-740

24. Defronzo RA (1981) Glucose intolerance and aging. Diabetes Care 4: 493-501

25. Hales CN, Desai M, Ozanne SE, Crowther NJ (1996) Fishing in the stream of diabetes: from measuring insulin to the control of fetal organogenesis. Biochem Soc Trans 24: 341-350

26. Ozanne SE, Wang CL, Coleman N, Smith GD (1996) Altered nuscle insulin sensitivity in the male offspring of protein-malnourished rats. Am J Physiol 271: E1128-E1134

27. Kahn SE, Prigeon RL, McCulloch DK et al. (1993) Quantification of the relationship between insulin sensitivity and beta-cell function in human subjects. Evidence for a hyperbolic function. Am J Physiol 42: 1663-1672

28. Hauge M (1981) The Danish Twin Register. In: Mednick SA, Baert AE, Bachmann BP (eds) Prospective longitudinal research. An empirical basis for the primary prevention of psychosocial disorders. Oxford University Press, Oxford, pp 217-221

29. Kyvik KO, Green A, Beck-Nielsen H (1995) The new Danish Twin Register: establishment and analysis of twinning rates. Int J Epidemiol 24: 589-596

30. Poulsen P, Kyvik KO, Vaag A, Beck-Nielsen H (1999) The heritability of non-insulin dependent diabetes mellitus (NIDDM) and abnormal glucose tolerance - a populationbased twin study. Diabetologia 42: 139-145

31. Hauge M (1981) The Danish Twin Register. In: Mednick SA, Baert AE, Bachmann BP (eds) Prospective longitudinal research. An empirical basis for the primary prevention of psychosocial disorders. Oxford University Press, Oxford, pp 217-221

32. Hemmilä I, Dakubu S, Mukkala V-M, Siitari H, Lövgren T (1984) Europium as a label in time-resolved immunoflourometric assays. Anal Biochem 137: 335-343 
33. Bjõro K Jr, Bjõro K (1985) Disturbed intrauterine growth in twins: etiological aspects. Acta Genet Med Gemellol (Roma) 34: 73-79

34. Naeye RL, Benirschke K, Hagstrom JWC, Marcus CC (1966) Intrauterine growth of twins as estimated from liveborn birth weight data. Pediatrics 37: 409-416

35. Wang X, Zuckerman B, Coffman GA, Corwin MJ (1995) Familial aggregation of low birth weight among whites and blacks in the United States. N Engl J Med 333: 1744 1749
36. Baird J, Osmond C, MacGregor A, Snieder H, Hales CN, Phillips DIW (2001) Testing the fetal origins hypothesis in twins: the Birmingham twin study. Diabetologia 44: 33-39

37. Lehtovirta M, Kaprio J, Forsblom C, Eriksson J, Tuomilehto J, Groop L (2000) Insulin and insulin secretion in monozygotic and dizygotic twins. Diabetologia 43: 285293

38. Phillips DI (1993) Twin studies in medical research: can they tell us whether diseases are genetically determined? Lancet 341: 1008-1009 